\title{
Analgesic Effects of Triterpenoid Saponins From Stauntonia chinensis via Selective Increase in Inhibitory Synaptic Response in Mouse Cortical Neurons
}

OPEN ACCESS

Edited by:

Jiahong Lu,

University of Macau, China

Reviewed by:

Wei Li,

Toho University, Japan

Lawrence Toll,

Florida Atlantic University,

United States

*Correspondence:

Guangzhong Yang

yanggz888@126.com

Xiaofei Yang

sunlittlefly@hotmail.com

tThese authors have contributed equally to this work

Specialty section:

This article was submitted to

Ethnopharmacology,

a section of the journal

Frontiers in Pharmacology

Received: 26 April 2018 Accepted: 24 October 2018 Published: 12 November 2018

Citation:

Chen S, Rong Y, Liu M, Cheng S,

Liu X, Li X, Yu Y, Yang G and Yang X (2018) Analgesic Effects

of Triterpenoid Saponins From

Stauntonia chinensis via Selective Increase in Inhibitory Synaptic

Response in Mouse Cortical Neurons.

Front. Pharmacol. 9:1302.

doi: 10.3389/fphar.2018.01302

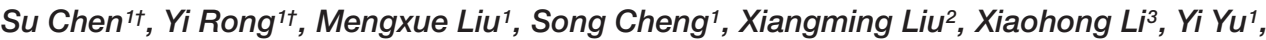 Guangzhong Yang ${ }^{4 *}$ and Xiaofei Yang ${ }^{1 *}$}

'Key Laboratory of Cognitive Science, Hubei Key Laboratory of Medical Information Analysis and Tumor Diagnosis \& Treatment, Laboratory of Membrane Ion Channels and Medicine, College of Biomedical Engineering, South-Central University for Nationalities, Wuhan, China, ${ }^{2}$ Gongqing Institute of Science and Technology, Gongqing, China, ${ }^{3}$ Department of Cancer, Liyuan Hospital, Tongji Medical College, Huazhong University of Science and Technology, Wuhan, China, ${ }^{4}$ Laboratory for Natural Products Chemistry, School of Pharmaceutical Sciences, South Central University for Nationalities, Wuhan, China

Triterpenoid saponins from Stauntonia chinensis (TSS) are potential therapeutic agents because of its analgesic properties. However, the underlying mechanisms of the antinociceptive activity of TSS are largely unclear, especially in CNS. The present study confirmed the analgesic effect of TSS using four models of acute pain based on thermal or chemical stimuli. TSS treatment specifically impaired the threshold of thermal- and chemical-stimulated acute pain. Naloxone did not block the anti-nociceptive effects of TSS, which showed no participation of the opioid system. We investigated the electrical signal in cultured cortical neurons to explore whether TSS treatment directly affected synaptic transmission. TSS treatment selectively increased spontaneous inhibitory synaptic release and GABA induced charge transfer in mouse cortical neurons. The effects of TSS were maintained for at least $8 \mathrm{~h}$ in cultured neurons and in injected mice. Taken together, our results suggest that the analgesic role of TSS in cortex occurs via a particular increase in the inhibitory synaptic response at resting state, which supports TSS as a potential candidate for inflammatory pain relief.

Keywords: anti-nociceptive activity, TSS, spontaneous release, hot-plate test, formalin test, capsaicin test

\section{INTRODUCTION}

Pain reduces the quality of life, and it is an economic burden to society. Medically opioids are primarily used for pain relief, including anesthesia. But most opioid drugs are controlled substances because of their reputation for addiction and fatal overdose (Al-Hasani and Bruchas, 2011). NSAIDs, such as aspirin, naproxen, ibuprofen, and acetaminophen, are the most commonly used as

Abbreviations: ACC, anterior cingulate cortex; AMPARs, AMPA-type glutamate receptors; E/I, excitation/inhibition; eIPSCs, evoked inhibitory postsynaptic currents; GAD65, glutamic acid decarboxylase 65; mEPSCs, miniature excitatory postsynaptic currents; mGluRs, G-protein-coupled glutamate receptors; mIPSCs, miniature inhibitory postsynaptic currents; NSAIDs, non-steroidal anti-inflammatory drugs; P0, postnatal day 0; RRP, readily releasable pool; TCM, traditional Chinese medicine; TRPA1, transient receptor potential A1; TRPV1, transient receptor potential cation channel subtype V1; TSS, triterpenoid saponins from Stauntonia chinensis. 
analgesic drugs (Simon, 2013; Moore et al., 2014). However, gastrointestinal toxicity is reported as side-effect of NSAIDs for a long time (Bjarnason and Macpherson, 1989; Klasser and Epstein, 2005; Gargallo and Lanas, 2013). To explore safer candidates for analgesia, TCM is widely considered as an alternative medical system (Xue et al., 2010; Liu et al., 2015).

Stauntonia chinensis DC. (Lardizabalaceae), an evergreen herb growing in southern China, is commonly known as "Ye Mu Gua." This herb is used as a TCM, especially for its anti-inflammatory and analgesic effects (Jiangsu New Medical College, 1977; Peng et al., 2003). The preparations, such as tablets and injections of Stauntonia chinensis DC, have been widely applied for the treatments of rheumatism arthralgia, postoperative analgesia, postherpetic and sciatic neuralgia clinically. Up to date, there have been several investigations aimed at studying the pharmacological mechanism of the anti-nociceptive and antiinflammatory activities produced by Stauntonia chinensis and finding the specific material basis for these utilizations.

Ying et al. (2014) demonstrated that the 60\% EtOH extract of Stauntonia chinensis was its active ingredients producing anti-nociceptive and anti-inflammatory activities. And the antiinflammatory activity of Stauntonia chinensis extracts was related to the reduction of PGE2 production. However, the antinociceptive and anti-inflammatory activities of one fraction were not entirely consistent, which indicated that inhibition of the inflammatory response may be one of the anti-nociceptive mechanisms of Stauntonia chinensis extracts (Ying et al., 2014).

Similar results were observed for NSAIDs. The well-known mechanisms of NSAIDs in inflammatory pain therapy are the inhibition of COX-1 and COX-2, which decreases the production of prostanoids (Alhouayek and Muccioli, 2014; Díaz-González and Sánchez-Madrid, 2015; Dwivedi et al., 2015). Furthermore, the roles of NSAIDs in neurodegenerative disease have recently gained further attention (Ferencik et al., 2001; Iwata et al., 2004; Ajmone-Cat et al., 2008), which indicates that the drugs used to attenuate pain may have direct or indirect effects on brain neurons.

Ye et al. (2003) demonstrated that the Stauntoniae saponin exhibited affinity for myelin sheaths and axon membranes and resulted in nerve structure destruction and conduction blockage. The glycoside extracts from Stauntonia chinensis which contained triterpenoid saponins (percentage content was 52.4\%) could protect injured spinal neurons and promote the growth of spinal neurons (Zhou and Ye, 2011). However, the mechanisms underlying the analgesic effects of triterpenoid saponins isolated from Stauntonia chinensis DC. (TSS) remain poorly understood, especially in central nerve system (CNS) (Jiangsu New Medical College, 1977).

The present study confirmed the analgesic effect of TSS using four models of acute pain based on thermal or chemical stimuli to clarify the direct effects of TSS treatment in the CNS.TSS treatment selectively increased spontaneous inhibitory synaptic transmission in cultured cortical neurons. Further investigation demonstrated a presynaptic, rather than postsynaptic, effect of TSS in neurons. The increased activity in inhibitory synapses lasted for at least $8 \mathrm{~h}$ after the TSS exposure. Moreover, except for acetic acid-induced writhing test, the hot-plate, formalin and capsaicin tests confirmed the analgesic effect $8 \mathrm{~h}$ after TSS injection as well. Naloxone did not block the anti-nociceptive effect of TSS in the hot-plate test, which demonstrated that the analgesic effect of TSS did not involve opioid receptor. Taken together, our results suggested that TSS could directly increase the inhibitory synaptic response in mice cortex neurons to enhance the thresholds of inflammatory pain. These results supported TSS as a potential candidate for inflammatory pain relief.

\section{MATERIALS AND METHODS}

\section{Extraction and Isolation of TSS}

The stems of Stauntonia chinensis were collected from NanNing, Guangxi Zhuang Autonomous Region, China and identified by associate chief pharmacist Jin-Wei Huang at Guangxi Institute of Minority Medicine. A voucher specimen (20090801) was deposited with the Herbarium of School of Pharmaceutical Sciences, South Central University for Nationalities. According to the previously reported method (Xu et al., 2018), the stems of Stauntonia chinensis ( $2.5 \mathrm{~kg}$ ) were extracted with $60 \% \mathrm{EtOH}$ three times and then successively partitioned with EtOAc and $n-\mathrm{BuOH}$. The extract of $n$-BuOH (109 g) was purified by HP-20 micro resin column chromatograpy to obtain TSS and the chemical composition of TSS was further analyzed by HPLC-ESI-MS/MS.

\section{Animals and Drugs}

Male and female Kunming mice weighing 18-22 g were obtained from Hubei Research Center of Laboratory Animals [Grade SPF, SCXK (Hubei) 2015-0018] and acclimatized to the laboratory conditions for at least 1 week prior to experimentation. The mice were housed at a temperature of $22 \pm 2^{\circ} \mathrm{C}$ under a $12 \mathrm{~h}$ light/12 h dark cycle (lights on at 7:00 AM, lights off at 7:00 PM) and maintained (5 animals per cage) with food and water ad libitum. Separate groups of mice were used for each analgesic test, and the animals were used only once in the experiments. All experimental procedures involving mice were performed under a protocol approved by the animal research ethics committee of South-Central University for Nationalities.

TSS was dissolved in isotonic $(0.9 \% \mathrm{NaCl})$ saline and administered intraperitoneally at 2,8 , and $20 \mathrm{mg} \cdot \mathrm{kg}^{-1}$, unless otherwise indicated. The following substances were used: morphine hydrochloride (Northeast Pharmaceutical Group Shenyang No. 1 Pharmaceutical Factory), naloxone hydrochloride (Beijing Hua Su Pharmaceutical Co., Ltd.), acetic acid, formalin, capsaicin (Sigma), and aspirin (Shenwei Pharmaceutical Co., Ltd.). All drugs were dissolved in isotonic saline, except capsaicin which was dissolved in absolute ethanol. The final concentration of ethanol did not exceed $10 \%$ and did not cause any per se effect. The dose volume of intraperitoneal injection was within a $10 \mathrm{ml} \cdot \mathrm{kg}^{-1}$ level for mice.

\section{Hot Plate Test and Acetic Acid-Induced Writhing Test}

The hot-plate test was used to measure response latencies according to the method described previously by 
Eddy and Leimbach (1953) with minor modification. Animals were placed into a glass cylinder and the time between placement and shaking or licking of the paws or jumping was recorded as the index of response latency. A full automatic thermal pain stimulator (BME-410C, Institute of Biomedical Engineering, Chinese Academy of Medical Sciences) was used. A cut-off time of $60 \mathrm{~s}$ was used to avoid tissue damage. Animals were selected $24 \mathrm{~h}$ in advance on the basis of reactivity. Mice that remained on the apparatus maintained at $55 \pm 0.5^{\circ} \mathrm{C}$ less than $5 \mathrm{~s}$ and beyond $30 \mathrm{~s}$ were eliminated. The hot-plate test was performed four times at different time points post-drug administration. Each animal was tested prior to drug administration using the same heat stimulus to determine the baseline. Negative control animals received the isotonic saline used to dilute the drugs and morphine ( $5 \mathrm{mg} \cdot \mathrm{kg}^{-1}$ intraperitoneally) was used as a positive control. Two groups of mice were pretreated with naloxone (1 $\mathrm{mg} \cdot \mathrm{kg}^{-1}$ intraperitoneally, a non-selective opioid receptor antagonist) $20 \mathrm{~min}$ prior to drug administration to assess the possible participation of the opioid system in the anti-nociceptive effect of TSS.

Abdominal constrictions were induced according to the procedures described previously by Spindola et al. (2010). Writhing movements were induced by an intraperitoneal injection of $0.8 \%$ acetic acid solution $\left(10 \mathrm{ml} \cdot \mathrm{kg}^{-1}\right)$. Mice were individually placed into glass cylinders with a $20 \mathrm{~cm}$ diameter, and writhing movements were counted for $15 \mathrm{~min}$ after acetic acid injection. Animals were pretreated with different doses of TSS $30 \mathrm{~min}$ before the injection of acetic acid. Aspirin (20 mg. kg-1 intraperitoneally) was used as a positive control. Negative control animals received a similar volume of isotonic saline.

\section{Formalin and Capsaicin Tests}

The procedure for formalin test was essentially the same as that described by Dubuisson and Dennis (1977). Twenty microliters of $5 \%$ formalin were injected into the dorsal surface of the right hind paw of mice. After the injection of formalin, the animals were immediately placed in a glass cylinder with a $20 \mathrm{~cm}$ diameter, and the time spent in licking the injected paw was monitored and recorded over for $0-5 \mathrm{~min}$ (early phase of licking) and 15-40 min (late phase of licking). The animals received different doses of TSS, aspirin ( $20 \mathrm{mg} \cdot \mathrm{kg}^{-1}$ intraperitoneally) and isotonic saline $30 \mathrm{~min}$ prior to formalin injection.

The method for the capsaicin test followed the procedure of Corrêa et al. (1996). Capsaicin $(20 \mu \mathrm{l})$ was injected intraplantarly (1.6 $\mu$ g per paw) into the ventral surface of the right hind paw of mice. Animals were observed individually for $5 \mathrm{~min}$ following capsaicin injection. The amount of time spent licking the injected paw was recorded using a chronometer and was considered as indicative of nociception. The mice were given different doses of TSS 30 min prior to capsaicin injection. Control animals received aspirin (20 mg. $\mathrm{kg}^{-1}$ intraperitoneally) and isotonic saline.

\section{Cell Culture}

The dissociated cortical neurons were prepared from randomly chosen P0 pups, as described previously (Gong et al., 2016). Briefly, the dissociated cortical neurons were dissected from P0 pups of WT Kunming mice, dissociated using $0.25 \%$ trypsinEDTA digestion for $12 \mathrm{~min}$ at $37^{\circ} \mathrm{C}$, plated on poly-L-lysine (Sigma)-coated 12-mm diameter circular glass coverslips, and cultured in MEM (Gibco) supplemented with $2 \mathrm{v} \cdot \mathrm{v}^{-1} \%$ B27 (Gibco), $0.5 \mathrm{w} \cdot \mathrm{v}^{-1} \%$ glucose, $100 \mathrm{mg} / \mathrm{l}$ transferrin, $5 \mathrm{v} \cdot \mathrm{v}^{-1} \%$ fetal bovine serum (Gibco), and $2 \mathrm{mM}$ Ara-C (Sigma). All animal procedures were performed in accordance with South-Central University for Nationalities animal use rules and the requisite approvals of animal use committees.

\section{mRNA Measurements and Immunocytochemistry}

mRNA measurements were performed with RNA isolated from cultured neurons at 14-15 days in vitro (DIV14-15). RT-PCR reactions were performed in triplicate with GAPDH as an internal control.

Mouse cortical neurons were fixed in $4 \%$ paraformaldehyde and permeabilized with $0.2 \%$ Triton X-100, stained with antiGAD65 (polyclonal; Sigma) and anti-MAP2 (monoclonal; Sigma) primary antibodies in PBS with 5\% BSA, and visualized using Alexa Fluor 488 goat anti-rabbit and Alexa Fluor 546 goat antimouse secondary antibodies (Molecular Probes). Images were acquired using a Nikon C2 confocal microscope equipped with a $60 \times$ oil-immersion objective. Identical settings were used for all samples in each experiment. We measured the average pixel intensities via manually tracing each dendrite, with a $>2$-fold background signal.

\section{Electrophysiological Recordings}

Electrophysiological recordings were performed in whole-cell patch-clamp mode using concentric extracellular stimulation electrodes. Patch pipettes were pulled from borosilicate glass capillary tubes (World Precision Instruments, Inc.) using a P-97 pipette puller. The resistance of pipettes filled with intracellular solution varied between 3 and $5 \mathrm{mOhm}$. After formation of the whole-cell configuration and equilibration of the intracellular pipette solution, the series resistance was adjusted to 8-10 mOhm. The whole-cell pipette solution contained $120 \mathrm{mmol} \cdot \mathrm{l}^{-1} \mathrm{CsCl}, 10 \mathrm{mmol} \cdot \mathrm{l}^{-1} \mathrm{HEPES}, 10 \mathrm{mmol} \cdot \mathrm{l}^{-1} \mathrm{EGTA}$, $0.3 \mathrm{mmol} \cdot \mathrm{l}^{-1} \mathrm{Na}-\mathrm{GTP}, 3 \mathrm{mmol} \cdot \mathrm{l}^{-1} \mathrm{Mg}$-ATP and $5 \mathrm{mmol} \cdot \mathrm{l}^{-1}$ QX-314 ( $\mathrm{pH} 7.2$, adjusted with $\mathrm{CsOH}$ ). The bath solution contained $140 \mathrm{mmol} \cdot \mathrm{l}^{-1} \mathrm{NaCl}, 5 \mathrm{mmol} \cdot \mathrm{l}^{-1} \mathrm{KCl}, 2 \mathrm{mmol} \cdot \mathrm{l}^{-1}$ $\mathrm{MgCl}_{2}, 2 \mathrm{mmol} \cdot \mathrm{l}^{-1} \mathrm{CaCl}_{2}, 10 \mathrm{mmol} \cdot \mathrm{l}^{-1} \mathrm{HEPES}-\mathrm{NaOH}$, and $10 \mathrm{mmol} \cdot \mathrm{l}^{-1}$ glucose ( $\left.\mathrm{pH} 7.4\right)$.

In all the recordings, neurons were voltage-clamped at $-70 \mathrm{mV}$. Synaptic currents were monitored with an EPC10 amplifier (HEKA). Evoked synaptic responses were recorded using a bipolar electrode placed $100-150 \mathrm{~mm}$ from the soma of neurons. Single extracellular stimulus pulses $(90 \mu \mathrm{A}$, $1 \mathrm{~ms}$ ) were controlled with a Model 2100 Isolated Pulse Stimulator (A-M Systems, Inc.) for all evoked measurements. IPSCs and EPSCs were pharmacologically isolated with the addition of the AMPA and NMDA receptor blockers CNQX $\left(20 \mu \mathrm{mol} \cdot \mathrm{l}^{-1}\right)$ and AP-5 $\left(50 \mu \mathrm{mol} \cdot \mathrm{l}^{-1}\right)$, respectively, or the GABAA receptor blocker picrotoxin $\left(50 \mu \mathrm{mol} \cdot \mathrm{l}^{-1}\right)$ in the extracellular solution. Spontaneous mIPSCs or mEPSCs were 
monitored in the presence of tetrodotoxin (TTX, $1 \mu \mathrm{mol} \cdot \mathrm{l}^{-1}$ ) to block action potentials. The data were digitized at $10 \mathrm{kHz}$ with a $2-\mathrm{kHz}$ low-pass filter. Miniature events were analyzed in Clampfit 10 (Molecular Devices) using the templatematching search and a minimal threshold of $5 \mathrm{pA}$. Each event was visually inspected for inclusion or rejection by an experimenter who was blinded to the recording condition. Sucrose-evoked release was triggered via a 30-s application of bath solution to which $0.5 \mathrm{~mol} \cdot \mathrm{l}^{-1}$ sucrose was added and also contained AP-5, CNQX, and TTX. GABA-evoked release was measured via a 20-s application of bath solution to which $200 \mu \mathrm{mol} \cdot \mathrm{l}^{-1}$ GABA was added. McN-A-343 (4-3chlorophenyl-carbamoyloxy-2-butynyltrimethylammonium, $50 \mu \mathrm{mol} \cdot \mathrm{l}^{-1}$ ) was dissolved in bath solution just before experiment.

\section{Statistical Analysis}

The data were expressed as the mean \pm SEM and analyzed with SPSS software (version 17.0) and Prism 6.01 (GraphPad). All results were submitted to one-way analysis of variance (ANOVA), considering as critical level $P<0.05$ to evaluate significant difference between the control and treated groups, followed by Dunnett's $t$-test (for Figures 2, 6) or to Student's $t$-test comparing each condition to the indicated control experiment. All of which are described in figure legends.

\section{RESULTS}

\section{Identification of Triterpenoid Saponins in the TSS by HPLC-ESI-MS/MS}

According to the previously reported results (Xu et al., 2018), nearly 36 peaks were detected from TSS. Twenty of these major peaks were identified by comparison of the molecular formulae and fragmentation patterns with reported data in the literature. Their structures of triterpene saponins were determined as depicted in Figure 1 and Table $\mathbf{1}$.

The aglycones were mainly composed of hederagenin, 30norhederagenin, akebonic acid and oleanic acid, and the sugar chain is composed of glucose, rhamnose, arabinose, xylose and glucuronic acid. The chromatographic behaviors of TSS in reverse phase chromatography depended on the polarities of their substituents. In general, bidesmoside triterpenoid glycosides (compounds 1-14) exhibited longer retention times than monodesmosides (compounds 15-20). On the other hand, TSS containing a 30-norhederagenin aglycon (compounds 15) eluted more rapidly than those containing a hederagenin aglycon (compounds 6-11). If TSS contain the same aglycon and sugar chain ether-linked to C-28(e.g., compounds 2-4 and 7-9), then the retention time became shorter with the increase in the number of sugars attached at C-3. However, compounds $\mathbf{1}$ and 6, which contained glucuronic acid, were exceptions due to their higher hydrophilicities.

\section{TSS Increased the Reaction Time of Mice in Hot Plate Test}

To observe the nociceptive activity of TSS on thermal-stimulated acute pain, five groups of 10 mice were respectively treated with isotonic saline, morphine and three doses of TSS. TSS (2 and $8 \mathrm{mg} \cdot \mathrm{kg}^{-1}$ ) did not produce significant alteration in the reaction time 30,60, and $90 \mathrm{~min}$ after the administration. TSS (20 mg. $\mathrm{kg}^{-1}$ ), however, produced a significant increase in the reaction time $30 \mathrm{~min}$ after the administration. Morphine, used as reference drug, produced a significant and marked analgesic effect in both models. The other two groups of 10 mice were pretreated with naloxone followed by morphine or $20 \mathrm{mg} \cdot \mathrm{kg}^{-1}$ TSS. Naloxone largely reversed the antinociception caused by injection of morphine, but it did not significantly alter the anti-nociceptive action of TSS. The detailed results were shown in Table 2. Our results showed that TSS could increase the threshold of thermal-stimulated acute pain via a mechanism that was not related to opioid receptor.

\section{TSS Reduced Acetic Acid-Induced Writhing Movements of Mice}

To discover the nociceptive activity of TSS on chemicalstimulated acute visceral pain, five groups of 10 mice
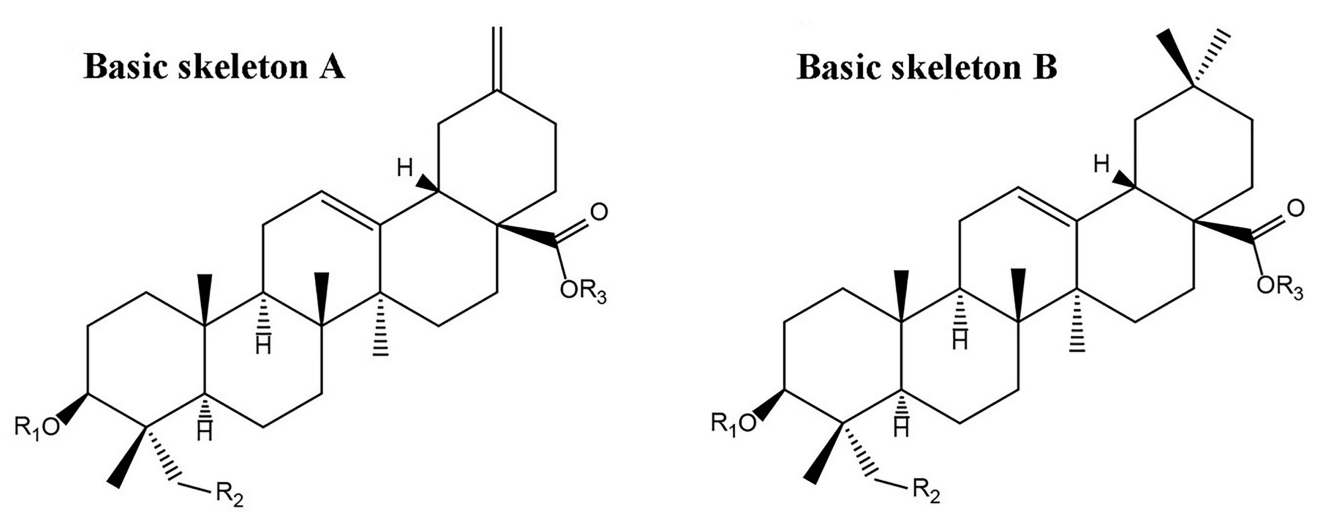

FIGURE 1 | Basis skeletons of chemical structures of triterpene saponins identified in TSS. 

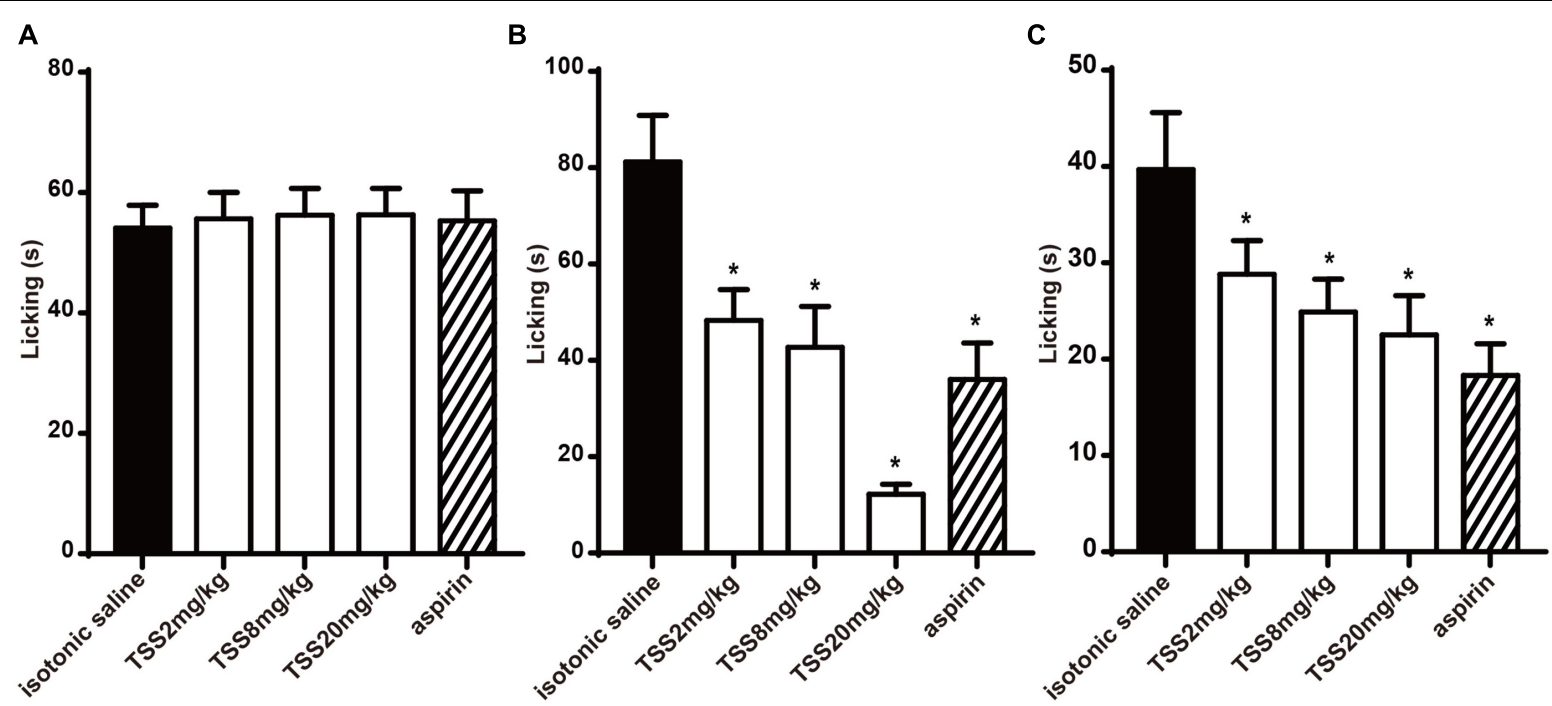

FIGURE 2 | Effect of TSS on formalin and capsaicin test. (A) Effect of TSS against formalin-induced licking in the first phase in mice. (B) Effect of TSS against formalin-induced licking in the second phase in mice. (C) Effect of TSS against capsaicin-induced licking in mice. Each column represented the mean of the values obtained in 10 mice and the error bars indicate the SEM. The closed columns indicated the control value (isotonic saline group), the open columns correspond to mice treated with TSS and the twill column indicated the positive control value (aspirin group). *Denote the significance levels, when compared with control group (one-way ANOVA), $P<0.05$.

TABLE 1 | Chemical structures of triterpene saponins identified in TSS.

\begin{tabular}{|c|c|c|c|c|}
\hline Compound & Basic skeleton & $\mathbf{R}_{\mathbf{1}}$ & $\mathbf{R}_{\mathbf{2}}$ & $\mathbf{R}_{3}$ \\
\hline 2 & $A$ & $-\operatorname{Ara}[(2 \leftarrow 1) \operatorname{Rha}](3 \leftarrow 1) \operatorname{Ara}$ & $\mathrm{OH}$ & $-\mathrm{Glc}(6 \leftarrow 1) \mathrm{Glc}(4 \leftarrow 1) \mathrm{Rha}$ \\
\hline 4 & A & -Ara & $\mathrm{OH}$ & $-\mathrm{Glc}(6 \leftarrow 1) \mathrm{Glc}(4 \leftarrow 1) \mathrm{Rha}$ \\
\hline $5^{*}$ & $A$ & -Ara $(2 \leftarrow 1) \operatorname{Rha}$ & $\mathrm{OH}$ & $-G|c(6 \leftarrow 1) G| c$ \\
\hline 6 & B & -Ara $(2 \leftarrow 1)$ GluA & $\mathrm{OH}$ & $-\mathrm{Glc}(6 \leftarrow 1) \mathrm{Glc}(4 \leftarrow 1)$ Rha \\
\hline 8 & B & $-\operatorname{Ara}(2 \leftarrow 1) \operatorname{Rha}$ & $\mathrm{OH}$ & $-\operatorname{Glc}(6 \leftarrow 1) \operatorname{Glc}(4 \leftarrow 1)$ Rha \\
\hline 9 & B & -Ara & $\mathrm{OH}$ & $-\mathrm{Glc}(6 \leftarrow 1) \mathrm{Glc}(4 \leftarrow 1) \mathrm{Rha}$ \\
\hline 10 & B & $-\operatorname{Ara}[(2 \leftarrow 1) \operatorname{Rha}](3 \leftarrow 1) \operatorname{Ara}$ & $\mathrm{OH}$ & $-G \mid c(6 \leftarrow 1) \mathrm{Glc}$ \\
\hline 11 & B & $-\operatorname{Ara}(2 \leftarrow 1) \operatorname{Rha}$ & $\mathrm{OH}$ & $-G \mid c(6 \leftarrow 1) \mathrm{Glc}$ \\
\hline 12 & A & $-\operatorname{Ara}[(2 \leftarrow 1) \operatorname{Rha}](3 \leftarrow 1) X y l$ & $\mathrm{H}$ & $-\mathrm{Glc}(6 \leftarrow 1) \mathrm{Glc}(4 \leftarrow 1) \mathrm{Rha}$ \\
\hline 13 & A & $-\operatorname{Ara}(2 \leftarrow 1) \operatorname{Rha}$ & $\mathrm{H}$ & $-\operatorname{Glc}(6 \leftarrow 1) \operatorname{Glc}(4 \leftarrow 1)$ Rha \\
\hline $17^{*}$ & $\mathrm{~B}$ & $-\operatorname{Ara}[(2 \leftarrow 1) \operatorname{Rha}](3 \leftarrow 1)$ GluA & $\mathrm{OH}$ & $\mathrm{H}$ \\
\hline 18 & $\mathrm{~B}$ & $-\operatorname{Ara}(2 \leftarrow 1) \operatorname{Rha}$ & $\mathrm{OH}$ & $\mathrm{H}$ \\
\hline 19 & A & $-\operatorname{Ara}[(2 \leftarrow 1) \operatorname{Rha}](3 \leftarrow 1) \operatorname{Ara}$ & $\mathrm{H}$ & $\mathrm{H}$ \\
\hline 20 & $\mathrm{~B}$ & $-\operatorname{Ara}[(2 \leftarrow 1) \operatorname{Rha}](3 \leftarrow 1)$ GluA & $\mathrm{H}$ & $\mathrm{H}$ \\
\hline
\end{tabular}

*New compound.

were respectively treated with isotonic saline, aspirin and three doses of TSS. In the acetic acid-induced writhing test, compared with isotonic saline treatment, TSS ( 8 and $20 \mathrm{mg} \cdot \mathrm{kg}^{-1}$ ) and aspirin decreased the number of acetic acid-induced writhing movements (Table 3), which indicated that TSS could relieve acetic acid-induced acute visceral pain.

\section{TSS Decreased the Time Spent in Licking the Injected Paw of Mice on Formalin and Capsaicin Tests}

For understanding the nociceptive activity of TSS on chemicalstimulated acute pain, five groups of 10 mice were respectively treated with isotonic saline, aspirin and three doses of TSS. In the 
TABLE 2 | Effect of TSS on hot plate test in mice.

\begin{tabular}{|c|c|c|c|c|c|}
\hline \multirow[t]{2}{*}{ Group } & \multirow[t]{2}{*}{ Dose(mg/kg) } & \multicolumn{4}{|c|}{ Reaction time(s) } \\
\hline & & $\begin{array}{c}\text { Before } \\
\text { administration }\end{array}$ & $\begin{array}{c}30 \text { min after } \\
\text { administration }\end{array}$ & $\begin{array}{c}60 \text { min after } \\
\text { administration }\end{array}$ & $\begin{array}{c}90 \text { min after } \\
\text { administration }\end{array}$ \\
\hline isotonic saline & l & $15.8 \pm 4.5$ & $15.7 \pm 4.5$ & $16.8 \pm 5.6$ & $17.5 \pm 5.2$ \\
\hline Morphine & 5 & $14.8 \pm 2.0$ & $27.3 \pm 3.8^{*}$ & $27.0 \pm 4.9^{*}$ & $24.7 \pm 4.2^{*}$ \\
\hline TSS & 2 & $13.9 \pm 5.5$ & $14.8 \pm 3.9$ & $17.1 \pm 4.1$ & $15.1 \pm 3.1$ \\
\hline TSS & 8 & $15.8 \pm 4.9$ & $16.5 \pm 5.4$ & $18.0 \pm 5.8$ & $18.7 \pm 5.4$ \\
\hline TSS & 20 & $15.9 \pm 2.1$ & $24.6 \pm 3.4^{*}$ & $16.8 \pm 4.3$ & $18.1 \pm 4.5$ \\
\hline Morphine and naloxone & 5 (morphine) 1 (naloxone) & $14.8 \pm 1.7$ & $16.0 \pm 4.9$ & $16.7 \pm 5.2$ & $15.9 \pm 3.2$ \\
\hline TSS and naloxone & 20(TSS) 1(naloxone) & $16.9 \pm 2.2$ & $24.9 \pm 4.2^{*}$ & $19.0 \pm 5.3$ & $17.1 \pm 5.1$ \\
\hline
\end{tabular}

${ }^{*} P<0.05$ versus isotonic saline group $(n=10)$.

TABLE 3 | Effect of TSS on acetic acid-writhing in mice.

\begin{tabular}{lcc}
\hline Group & Dose $(\mathbf{m g} / \mathbf{k g})$ & Mean number of writhing mouse 15 $\mathbf{~ m i n}$ \\
\hline Isotonic saline & $/$ & $40.3 \pm 5.4$ \\
Aspirin & 20 & $10.6 \pm 2.6^{*}$ \\
TSS & 2 & $37.0 \pm 3.7$ \\
TSS & 8 & $26.5 \pm 5.6^{*}$ \\
TSS & 20 & $24.0 \pm 4.2^{*}$ \\
\hline
\end{tabular}

${ }^{*} P<0.05$ versus isotonic saline group $(n=10)$.

formalin test, the time spent in licking the injected paw in the first and second phases were $54.1 \pm 3.8$ and $81.2 \pm 9.7$ s respectively in control mice. Figure $\mathbf{2 A}$ showed that TSS and aspirin did not reduce the time spent in licking the injected paw in the first phase. However, TSS caused a marked and dose-related inhibition in the second phase of formalin-induced licking (Figure 2B). Aspirin was also anti-nociceptive in the second phase. Results showed that TSS could relieve formalin -induced acute inflammatory pain.

In the capsaicin test, five groups of 10 mice were respectively treated with isotonic saline, aspirin and three doses of TSS. TSS decreased the time spent in licking the injected paw in a dose-dependent manner. The capsaicin-induced pain was also inhibited significantly by aspirin (Figure 2C). These results showed that TSS could relieve capsaicin-induced acute neuropathic pain.

\section{TSS Exposure Selectively Increased Spontaneous Inhibitory Synaptic Response}

Considering the TSS treatment might affect the brain directly in the process of pain relief, we measured the neurotransmitter release in cultured mouse cortical neurons. To confirm our cultured neurons were capable to exhibit the synaptic activity properly and sensitive to certain drugs that altered synaptic transmission, McN-A-343 (Koga et al., 2017), which is selective for the muscarinic $M_{1}$ receptor, was used. Similarly, the frequency but not amplitude of mIPSCs in our cultured neurons was increased by McN-A-343 (Supplementary Figure S1), which indicated that our cultured neurons were able to precisely reflect synaptic release and alternation. After confirming the availability of our cortical neurons, the spontaneous response was characterized after incubation with $10 \mu \mathrm{g} \cdot \mathrm{ml}^{-1}$ TSS for $60 \mathrm{~min}$. Interestingly, the frequency and amplitude of mIPSCs were both significantly increased by TSS (Figure 3A). Whereas the frequency and amplitude of mEPSCs were not altered (Figure 3B), which suggested that TSS could act on brain neurons directly. To further test the effects of TSS on primary neurons, the action-potential evoked-IPSCs and evokedEPSCs mediated by AMPARs were measured. Similarly, the amplitude of evoked-EPSCs was unchanged by $10 \mu \mathrm{g} \cdot \mathrm{ml}^{-1}$ TSS treatment (Figure 3D), which confirmed that TSS had no effect on excitatory terminals. On the other hand, the amplitude of evoked-IPSCs was slightly, although not significantly, increased by $10 \mu \mathrm{g} \cdot \mathrm{ml}^{-1}$ TSS (Figure 3C). This result confirmed that TSS affected the inhibitory synaptic response. However, the difference between spontaneous and actionpotential evoked responses in inhibitory synapses suggested that TSS played a preferential role at the resting stage to continuously increase the threshold of pain at basal levels rather than transiently altering the threshold of pain with stimuli.

Then we asked if the effects of TSS in inhibitory synapses were time or dose dependent. For this purpose, the frequency of mIPSCs was tested after different time of TSS exposure. Our results revealed that 60 or $90 \mathrm{~min}$ of $10 \mu \mathrm{g} \cdot \mathrm{ml}^{-1}$ TSS exposure increased the frequency of mIPSCs but $30 \mathrm{~min}$ of TSS treatment did not (Figure 3E), indicating the increasing threshold of pain reflected by an increase inhibitory synaptic response induced by TSS took $1 \mathrm{~h}$ or so. On the other hand, the frequency of mEPSCs was kept unchanged with 30,60, or $90 \mathrm{~min}$ of $10 \mu \mathrm{g} \cdot \mathrm{ml}^{-1}$ TSS treatment (Supplementary Figure S2), confirming the effects of TSS were specific in inhibitory synapses. Therefore, $60 \mathrm{~min}$ TSS exposure was used for all the following experiments. Moreover, the effects of different concentration of TSS were next quantitated. $10 \mu \mathrm{g} \cdot \mathrm{ml}^{-1}$ or $20 \mu \mathrm{g} \cdot \mathrm{ml}^{-1}$ but not $1 \mu \mathrm{g} \cdot \mathrm{ml}^{-1}$ TSS treatment increased the frequency of mIPSCs (Figure 3F), suggesting a dose dependent regulation of TSS treatment. To minimize any potential side-effect of TSS treatment, we used $10 \mu \mathrm{g} \cdot \mathrm{ml}^{-1}$ TSS, the concentration could already increase the threshold of pain, for all the following measurements. 
A

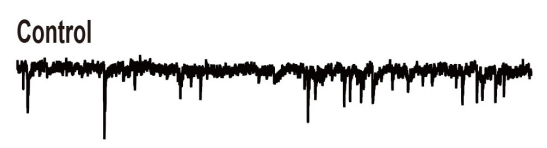

TSS

"rit"<smiles>CCCCC</smiles>

mini-IPSC
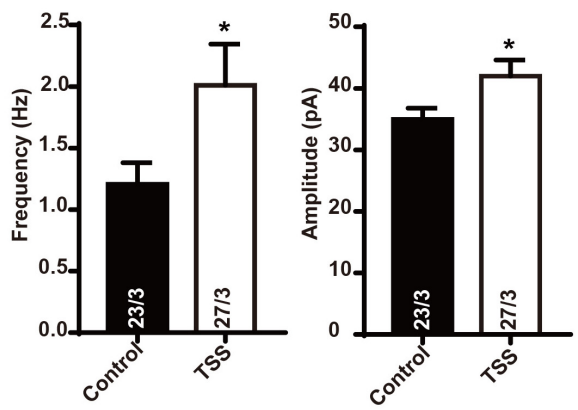

B

mini-EPSC

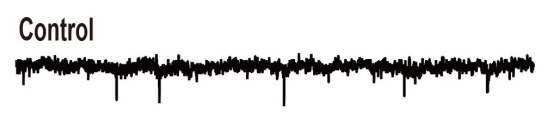

TSS

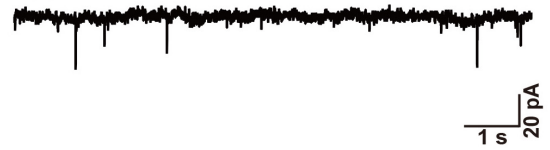

C

$$
\text { evoked-IPSC }
$$
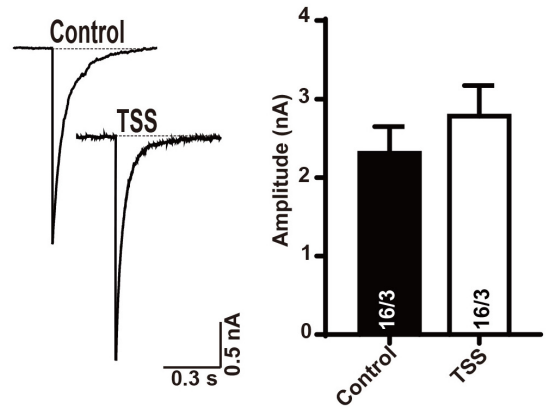

E

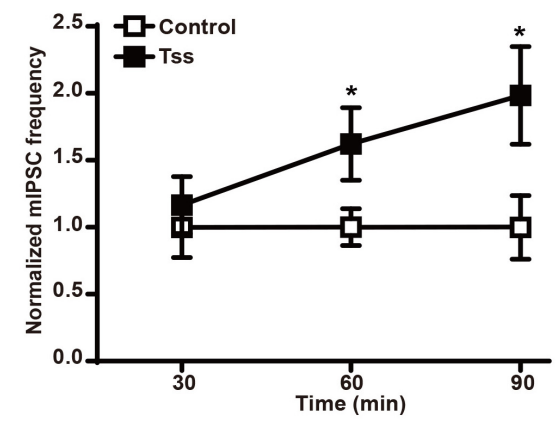

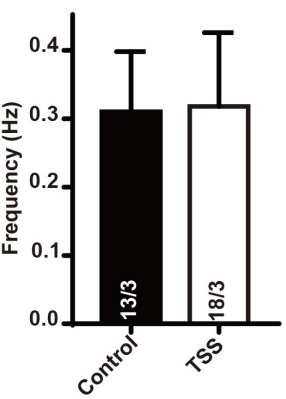

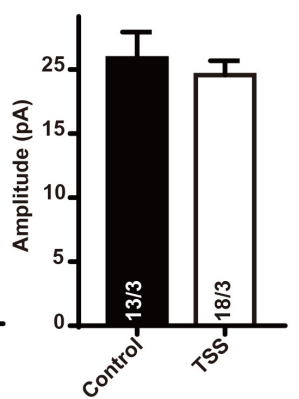

D

\section{evoked-EPSC}
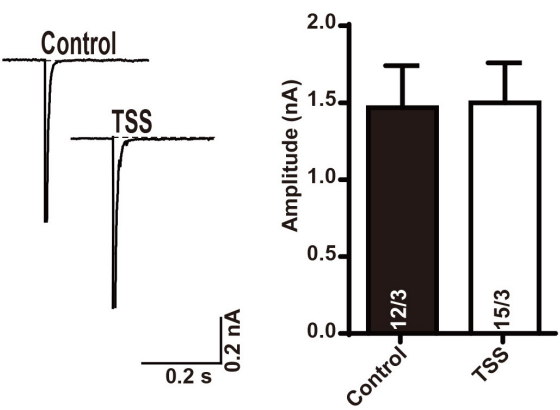

F

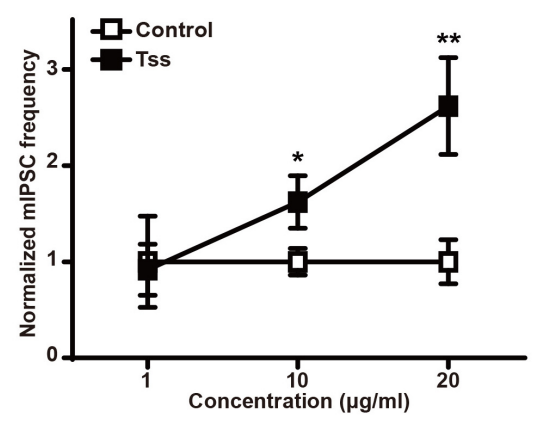

FIGURE 3 | TSS treatment selectively enhanced the response of inhibitory synapses. (A) Sample traces (left) and summary graphs of the frequency (middle) and amplitude (right) of mIPSCs recorded in cultured cortical neurons treated with (TSS) or without (Control) $10 \mu \mathrm{g} \cdot \mathrm{ml}^{-1} \mathrm{TSS}_{\text {for }} 60$ min. (B) Sample traces (left) and summary graphs of the frequency (middle) and amplitude (right) of mEPSCs recorded in neurons as described for (A). (C) Sample traces (left) and summary graphs of the amplitude (right) of eIPSCs recorded in neurons as described for (A). (D) Sample traces (left) and summary graphs of the amplitude (right) of eEPSCs recorded in neurons as described for (A). (E) Plot of cultured cortical neurons treated with $10 \mu \mathrm{g} \cdot \mathrm{ml}^{-1}$ TSS for 30, 60, and 90 min, respectively. (F) Plot of cortical neurons treated with $1 \mu \mathrm{g} \cdot \mathrm{ml}^{-1}, 10 \mu \mathrm{g} \cdot \mathrm{ml}^{-1}$ and $20 \mu \mathrm{g} \cdot \mathrm{ml}^{-1}$ TSS for $60 \mathrm{~min}$, respectively. Data shown in summary graphs are means \pm SEM. For (A-D), numbers of cells/independent cultures analyzed are listed in the bars. Three independent experiments were performed for $E$ and $F$. Statistical assessments were performed by the Student's $t$-test comparing each condition to the indicated control experiment $\left({ }^{*} P<0.05,{ }^{* *} P<0.01\right)$. 


\section{TSS Treatment Increased the Inhibitory Presynaptic Release Probability}

The increase in the frequency and amplitude of mIPSCs induced by TSS treatment indicated both pre- and postsynaptic roles for TSS. Therefore, the pre- and postsynaptic effects of TSS were differentiated. We stained neurons with antibodies to MAP2 and glutamic acid decarboxylase 65 (GAD65, an inhibitory presynaptic marker) to selectively visualize inhibitory nerve terminals. Quantitation of immunofluorescence revealed that the density and size of inhibitory synapses were unchanged after TSS treatment (Figure 4A), which suggested that the synapses themselves were not altered by TSS. The size of the RRP of vesicles from the synaptic responses induced by application of a hypertonic sucrose solution (Rosenmund and Stevens, 1996) was further tested. Similarly, no obvious difference in RRP size was detected with TSS treatment (Figure 4B), which indicated that the presynaptic priming ability was not impaired by TSS. Since the synapses number and the amount of releasable vesicles at each synapse were not altered by TSS, the most possible reason for increased mIPSCs frequency was an increase in the release probability after TSS treatment. Moreover, the slight increase observed in eIPSCs amplitude also consistent with this hypothesis.

\section{TSS Treatment Enhanced GABA Receptor Activity}

After demonstrating the presynaptic effect of TSS, we investigated whether TSS had postsynaptic effect as well. We performed quantitative RT-PCR measurements of GABAA receptor in cultured cortical neurons with or without TSS exposure. The measured relative mRNA levels were normalized to GAPDH (Figure 4C). Our results revealed that TSS treatment did not change the expression of GABAA receptor. To test whether TSS treatment directly affected postsynaptic GABAergic response, we then measured GABA-induced charge transfer. Interestingly, TSS exposure significantly increased the total charge transfer with $200 \mu \mathrm{mol} \cdot \mathrm{l}^{-1}$ GABA application (Figure 4D). Therefore, our results clarified that TSS treatment increased GABA induced charge transfer but not the expression of GABAA receptor, which indicated an increased postsynaptic GABAergic response induced by TSS.

\section{Effects of TSS at Inhibitory Synapses Sustained at Least $8 \mathrm{~h}$}

Since TSS treatment increased the basal inhibitory response in brain neurons to enhance the threshold of pain, we investigated the effective time period of TSS. We first treated cultured neurons with $10 \mu \mathrm{g} \cdot \mathrm{ml}^{-1}$ TSS for $60 \mathrm{~min}$, and then incubated the neurons in normal growth medium for different time. Our results revealed that the increased frequency of mIPSCs induced by TSS treatment was observed after 4 (Supplementary Figure S3A) and $8 \mathrm{~h}$ (Figures 5A-C) of recovery. However, the increase in mIPSCs frequency vanished after $12 \mathrm{~h}$ of recovery (Supplementary Figure S3B).
Therefore, our results suggested that the increased threshold induced by TSS sustained for at least $8 \mathrm{~h}$. Interestingly, not like the mIPSCs frequency, the amplitude of mIPSCs was not increased after recovery (Figures 5A-C and Supplementary Figure S3). Therefore, the presynaptic effect reflected as increased mIPSCs frequency kept longer than the postsynaptic effect reflected as increased mIPSCs amplitude, which suggested that the presynaptic effect was the dominant role of TSS.

\section{Effects of TSS in Hot Plate, Formalin and Capsaicin Tests Sustained for $\mathbf{8} \mathbf{~ h}$}

To further confirm the effective time of TSS, we investigated whether TSS (20 mg. $\mathrm{kg}^{-1}$ intraperitoneally) exhibited an antinociceptive effect $8 \mathrm{~h}$ after the administration using hot plate test, acetic acid-induced writhing test, formalin test and capsaicin test. In hot plate test, TSS produced a significant increase in the reaction time $8 \mathrm{~h}$ after the administration and the pretreatment of mice with naloxone did not change the anti-nociceptive action of TSS (Figure 6A). Our previous results showed that TSS $\left(20 \mathrm{mg} \cdot \mathrm{kg}^{-1}\right.$ ) could only induce an increase in the reaction time $30 \mathrm{~min}$ but not 60 or $90 \mathrm{~min}$ after the administration in hot plate test. The short term and long term effects of TSS seem contradictory. To figure out the nature of TSS treatment, we reselected 30 mice and tested their reaction times $30,60,90 \mathrm{~min}$, 2,4 , and $8 \mathrm{~h}$ after the TSS $\left(20 \mathrm{mg} \cdot \mathrm{kg}^{-1}\right)$ administration in parallel, respectively. Consistently, an increased reaction time was observed $30 \mathrm{~min}$ but not 60 or $90 \mathrm{~min}$ after the administration. However, the analgesic effect re-appeared after $2 \mathrm{~h}$ and remained until 8 h (Supplementary Figure S4). One possible explanation was that the analgesic effect of TSS in hot plate test had one fast phase and another slow but long lasting phase. These two phases of analgesic effects may occur via different modulation mechanisms, and cortex was likely involved in the slow phase of the 60-min or longer reaction time.

However, in acetic acid-induced writhing test, TSS could not change the number of acetic acid-induced writhing movements $8 \mathrm{~h}$ after the administration. The mean numbers of acetic acidinduced writhing movements $8 \mathrm{~h}$ after the administration in isotonic saline group and TSS group were $38.0 \pm 6.5$ and $42.9 \pm 4.4$, respectively $(P>0.05)$. In formalin test and capsaicin test, TSS reduced the time spent in licking the injected paw with formalin in the second phase (Figure 6B) and that induced by capsaicin (Figure 6C). All the results showed TSS could relieve thermal-stimulated pain, chemical-stimulated inflammatory pain and chemical-stimulated neuropathic pain except for chemicalstimulated visceral pain $8 \mathrm{~h}$ after the administration.

\section{DISCUSSION}

Nociceptive pain is an important early warning sign to avoid tissue damage caused by intense, potentially harmful stimuli. Electrical activity in nociceptive pain is initiated via ion channels such as the TRPV1 and voltage-gated sodium channels (Laedermann et al., 2013; Mickle et al., 2015). However, neuropathic and inflammatory pain occur after tissue damage 

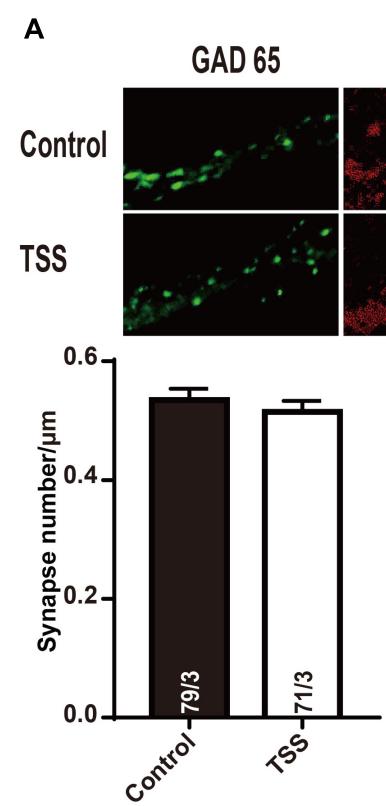

MAP2
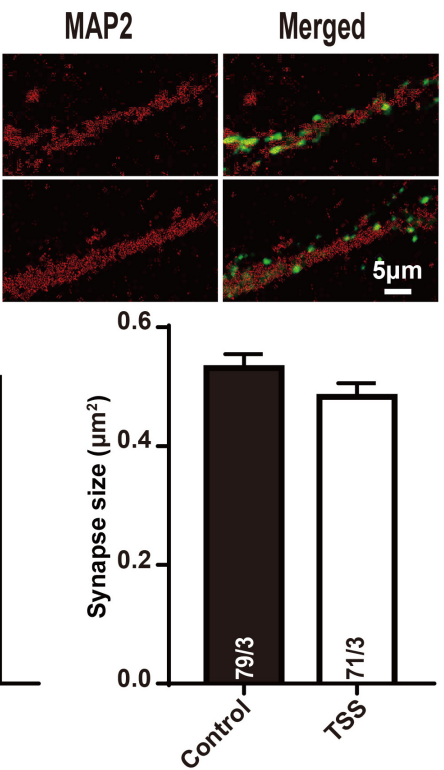

B

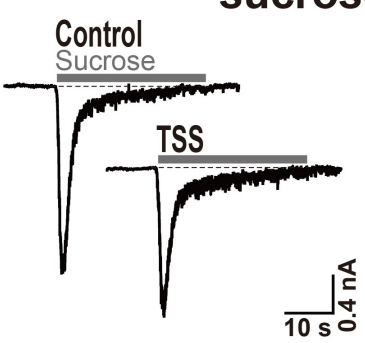

C $D$

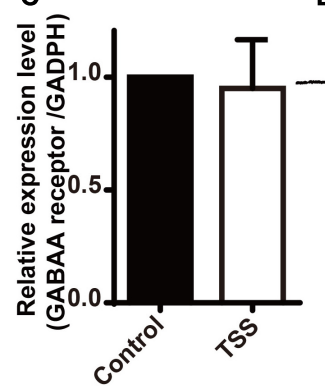

\section{IPSC}

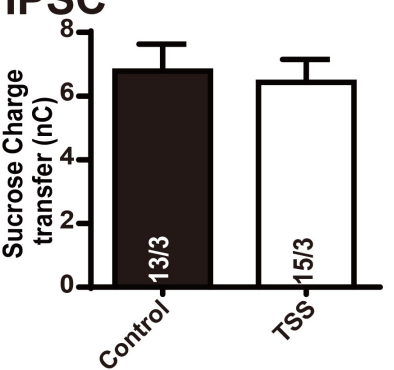

Control GABA
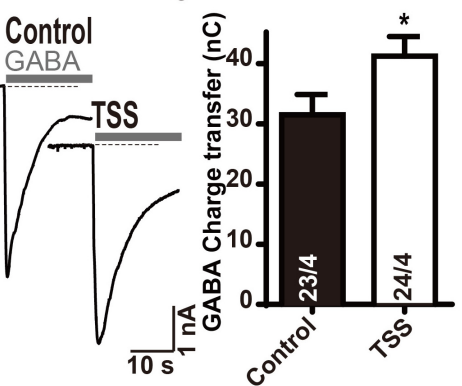

FIGURE 4 | The postsynaptic GABA response was specifically increased by TSS treatment. (A) Representative images (up) and summary graphs of synapse density (left lower) and cluster size (right lower) in cultured mouse cortical neurons treated with (TSS) or without (Control) $10 \mu \mathrm{g} \cdot \mathrm{ml}{ }^{-1} \mathrm{TSS}$ for $60 \mathrm{~min}$. The scale bar in right lower corner applies to all images. (B) Sample traces (left) and summary graphs (right) of IPSCs evoked by 0.5 mol. $\left.\right|^{-1}$ sucrose, recorded in neurons as described for (A). (C) Measurements of GABAA receptor mRNA levels in neurons as described for (A). (D) Sample traces (left) and charge transfer (right) induced by application of $200 \mu \mathrm{mol} \cdot \mathrm{I}^{-1}$ GABA in neurons as described for (A). Data shown in summary graphs are means \pm SEM. For (AB,D), numbers of cells/independent cultures analyzed are listed in the bars. Four independent experiments were performed for (C). Statistical assessments were performed by the Student's $t$-test comparing each condition to the indicated control experiment $\left({ }^{*} P<0.05\right)$.

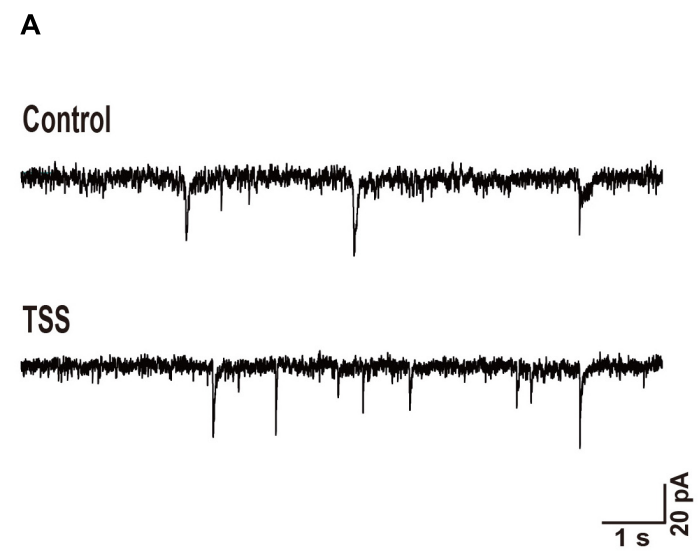

B

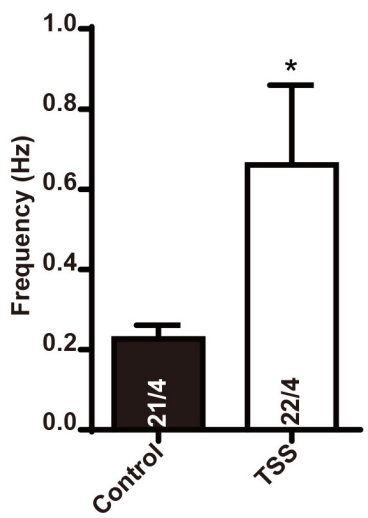

C

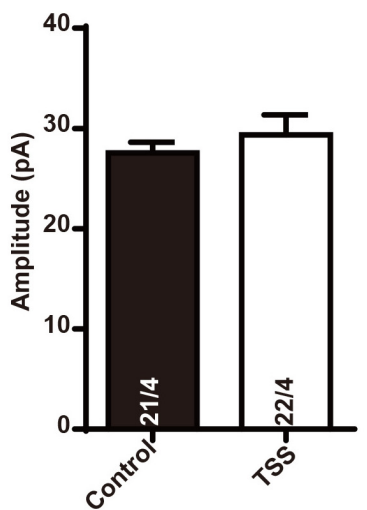

FIGURE 5 | The effect of TSS on inhibitory synaptic transmission was maintained for $8 \mathrm{~h}$. Sample traces (A) and summary graphs of the frequency (B) and amplitude (C) of mIPSCs recorded in cultured mouse cortical neurons with $8 \mathrm{~h}$ recovery after treated with (TSS) or without (Control) $10 \mu \mathrm{g} \cdot \mathrm{ml}{ }^{-1}$ TSS for 60 min. Data shown in summary graphs are means \pm SEM. Numbers of cells/independent cultures analyzed are listed in the bars. Statistical assessments were performed by the Student's $t$-test comparing each condition to the indicated control experiment $\left({ }^{*} P<0.05\right)$.

(Marchand et al., 2005). Multiple chemical mediators are released from injured cells and recognized by receptors, which increases the sensitivity of neurons and aggravates the pain (Basbaum et al., 2009; Chen et al., 2013).

The sensitivity of primary nociceptors was enhanced by PKA and PKC pathway activated by the interaction of inflammatory mediators and GPCRs in the periphery. On the other hand, dorsal horn neurons increased the excitability and then transferred the signal to brain. Glutamate receptors, which include ionotropic AMPA, NMDA and kainate receptors and metabotropic mGluRs, may underline the increased excitability (Dougherty and Willis, 1992; Schaible et al., 2002). AMPA and NMDA receptor antagonists reduced the sensitivity of spinal neurons (Schaible et al., 1991; Dougherty et al., 1992; Ren et al., 1992). Ca ${ }^{2+}$ influxes 

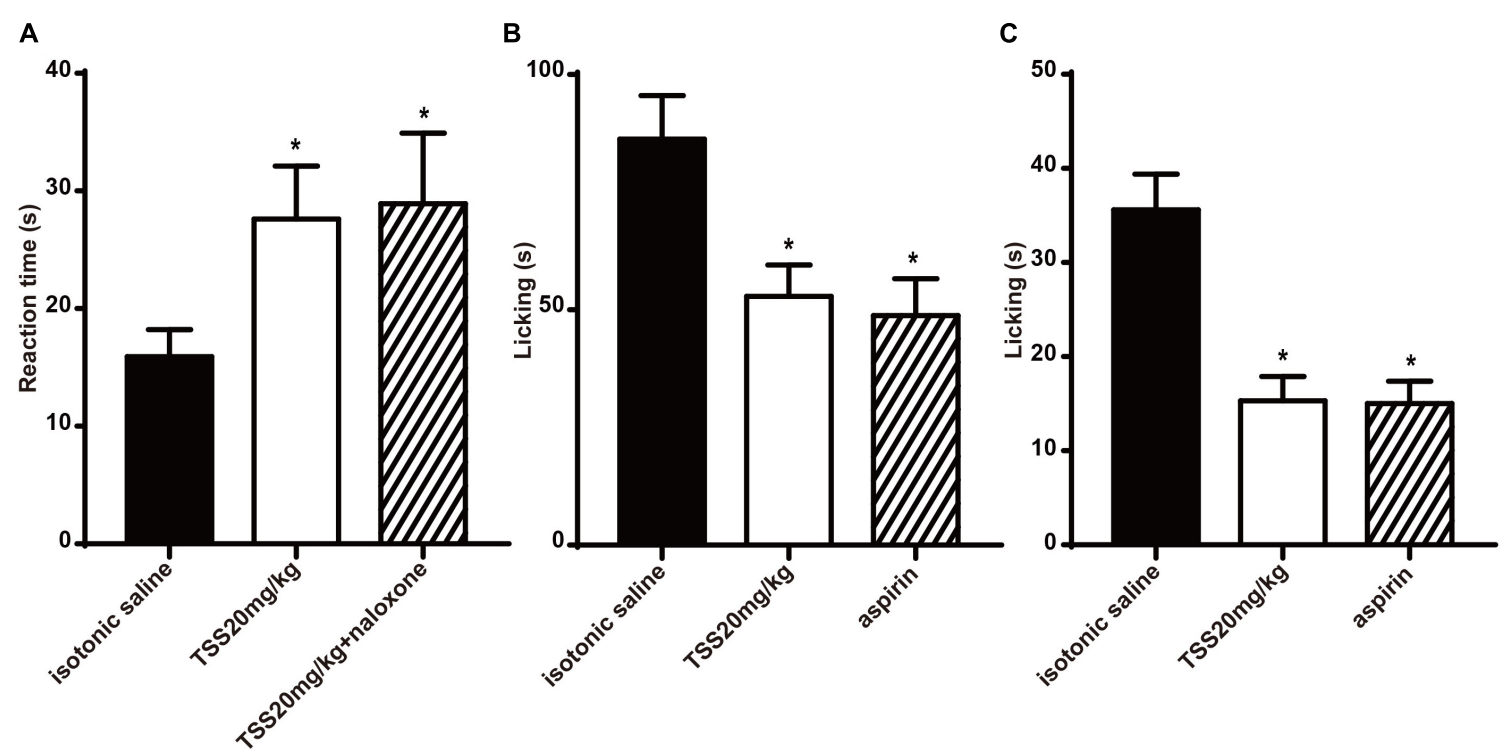

FIGURE 6 | Effects of TSS in hot plate, formalin and capsaicin test sustained at least $8 \mathrm{~h}$. (A) Effect of TSS on thermal-stimulated acute pain 8 h after the administration and the pretreatment of mice with naloxone did not change the anti-nociceptive action caused by TSS. (B) Effect of TSS against formalin-induced licking in the second phase in mice $8 \mathrm{~h}$ after the administration. (C) Effect of TSS against capsaicin-induced licking in mice $8 \mathrm{~h}$ after the administration. Each column represented the mean of the values obtained in 10 mice and the error bars indicate the SEM. The closed columns indicated the control value (isotonic saline group), the open column correspond to mice treated with TSS and the twill column indicated the positive control value. *Denote the significance levels, when compared with control group (one-way ANOVA), $P<0.05$.

also activated intracellular phosphorylation signal pathways to phosphorylate glutamate receptors, which modulated the activity or localization of these receptors (Caudle et al., 2005; Ji et al., 2009). Therefore, $\mathrm{Ca}^{2+}$ dependent synaptic release was clearly involved in the regulation of neuropathic and inflammatory pain. Needless to say, a downregulation of the hypersensitivity of peripheral terminals and brain neurons is a common method to relieve neuropathic and inflammatory pain.

In the pain therapy, TCM was considered as a promising alternate. The analgesic effects of TCM were intensively investigated due to their safety and efficacy. For instance, $\mathrm{Wu}-$ tou decoction, a classic TCM formula with anti-inflammatory activity, was explored to reduce the expression of TRPV1 and the TRPA1 in dorsal root ganglia, therefore inhibiting chronic pain (Wang et al., 2015). The aqueous extract of Flos populi exhibited significant anti-inflammatory activity against cotton pellet-induced granuloma and analgesic activity in the hot-plate test (Xu et al., 2014). Moreover, in the formalin assay, dehydrocorybulbine reduced the time spent licking in both early and late phase, which indicated a role in antinociceptive activity (Zhang et al., 2014). Thousands of years of use accumulated a large number of effective compounds of TCM, which offered an opportunity to identify new analgesic compounds.

Here, we demonstrated that 30 -min TSS administration effectively increased the reaction time of mice in hot plate test, decreased the number of acetic acid-induced writhing movements of mice, and reduced the time spent licking the paw injected with formalin and capsaicin, which supported an analgesic activity of TSS. To further explore the analgesic mechanisms of TSS in brain, we recorded the neurotransmitter release after TSS treatment in mouse cortical neurons and found that the spontaneous inhibitory activity was selectively increased by TSS. The postsynaptic response induced by application of GABA was also increased by TSS. Moreover, we demonstrated that the analgesic activity of TSS could sustain for $8 \mathrm{~h}$. The pretreatment of mice with naloxone did not change the anti-nociceptive action of TSS, which suggested that the opioid system did not take participation in the anti-nociceptive effect of TSS. Therefore, our results clarified that the analgesic effect of TSS in the brain was due to the enhanced activating threshold caused by increased inhibitory synaptic response, especially in the long term regulation.

Why is cortex important in the pain modulation? Pain, mediated by multiple cellular and molecular mechanisms, was extremely complicated. One single mechanism or area is hard to explain pain at all levels from spinal cord to brain. There were many regions in nerve system involved in pain, such as spinal cord, periaqueductal gray, amygdaloid nucleus and so on. However, the importance of cortex in pain modulation was contiguously reported. Different cortical regions such as ACC, insular cortex, primary and secondary somatosensory cortex and prefrontal cortex could be activated by various noxious stimuli (Talbot et al., 1991; Apkarian et al., 2005; Bushnell et al., 2013; Bliss et al., 2016). Altering the hyperexcitability of cortical pyramidal neurons played a role in the development of neuropathic pain (Xiong et al., 2017). Painful stimuli 
disturbed the balance between excitatory and inhibitory synaptic transmission in ACC (Gong et al., 2010). Here, we revealed that TSS treatment altered the synaptic activity of cultured mouse cortical neurons, which confirmed the involvement of cortex in neuropathic and inflammatory pain. However, our results did not exclude the possibility of the involvement of other regions in pain modulation.

The selective increase in spontaneous inhibitory synaptic responses induced by TSS raised another question that whether the E/I balance directly correlated to the regulation of pain sense. Glutamate and GABA systems were known to generate the opposite forces in neurotransmission and played key roles to the proper function of the CNS. Previous studies showed that $\alpha$-asarone enhanced GABAergic neurotransmission but decreased glutamatergic release to restore the E/I balance and inhibit the chronic inflammatory pain induced by hind-paw injection of complete Freund's adjuvant (Tian et al., 2017). The expression level of cytoplasmic polyadenylation element binding protein 1 was reported to correlate to presynaptic E/I release in the regulation of chronic pain (Yue et al., 2017). Furthermore, $\mathrm{E} / \mathrm{I}$ balance was suggested to play a role in vestibular migraine (Espinosa-Sanchez and Lopez-Escamez, 2015). The present study revealed that both presynaptic inhibitory release probability and postsynaptic GABA receptor activity were enhanced by TSS treatment, whereas the glutamatergic neurotransmission was unchanged, which confirmed that the importance of E/I balance in the regulation of neuropathic and inflammatory pain.

\section{CONCLUSION}

Our observations supported the use of TSS as an analgesic agent. Further investigations are needed to isolate specific effective analgesic components from TSS and determine the

\section{REFERENCES}

Ajmone-Cat, M. A., Cacci, E., and Minghetti, L. (2008). Nonsteroidal anti-inflammatory drugs and neurogenesis in the adult mammalian brain. Curr. Pharm. Des. 14, 1435-1442. doi: 10.2174/1381612087844 80199

Al-Hasani, R., and Bruchas, M. R. (2011). Molecular mechanisms of opioid receptor-dependent signaling and behavior. Anesthesiology 115, 1363-1381. doi: 10.1097/ALN.0b013e318238bba6

Alhouayek, M., and Muccioli, G. G. (2014). COX-2-derived endocannabinoid metabolites as novel inflammatory mediators. Trends Pharmacol. Sci. 35, 284292. doi: 10.1016/j.tips.2014.03.001

Apkarian, A. V., Bushnell, M. C., Treede, R. D., and Zubieta, J. K. (2005). Human brain mechanisms of pain perception and regulation in health and disease. Eur. J. Pain 9, 463-484. doi: 10.1016/j.ejpain.2004. 11.001

Basbaum, A. I., Bautista, D. M., Scherrer, G., and Julius, D. (2009). Cellular and molecular mechanisms of pain. Cell 139, 267-284. doi: 10.1016/j.cell.2009. 09.028

Bjarnason, I., and Macpherson, A. (1989). The changing gastrointestinal side effect profile of non-steroidal anti-inflammatory drugs. A new approach for the prevention of a new problem. Scand. J. Gastroenterol. Suppl. 163, 56-64. doi: $10.3109 / 00365528909091176$ underlying molecular mechanisms of the components in analgesia.

\section{ETHICS STATEMENT}

We indicate that the research were conducted under a protocol approved by the animal research ethics committee of SouthCentral University for Nationalities. All animal experiments were carried out in accordance with the National Institutes of Health guide for the care and use of Laboratory animals (NIH Publications No. 8023, revised 1978).

\section{AUTHOR CONTRIBUTIONS}

SuC and YR carried out the experiments and wrote the manuscript. ML, SoC, XiaoL, and YY performed the study. XianL, GY, and XY contributed to the planning of the work and wrote the paper.

\section{FUNDING}

This work was supported by the National Science Foundation of China (31670850 to XY and 81403186 to SuC), the Fundamental Research Funds for the Central Universities from South-Central University for Nationalities (CZQ18015) and the National Major New Drugs Innovation and Development (2017ZX09301060).

\section{SUPPLEMENTARY MATERIAL}

The Supplementary Material for this article can be found online at: https://www.frontiersin.org/articles/10.3389/fphar. 2018.01302/full\#supplementary-material

Bliss, T. V., Collingridge, G. L., Kaang, B. K., and Zhuo, M. (2016). Synaptic plasticity in the anterior cingulate cortex in acute and chronic pain. Nat. Rev. Neurosci. 17, 485-496. doi: 10.1038/nrn.2016.68

Bushnell, M. C., Ceko, M., and Low, L. A. (2013). Cognitive and emotional control of pain and its disruption in chronic pain. Nat. Rev. Neurosci. 14, 502-511. doi: 10.1038/nrn3516

Caudle, R. M., Perez, F. M., Del Valle-Pinero, A. Y., and Iadarola, M. J. (2005). Spinal cord NR1 serine phosphorylation and NR2B subunit suppression following peripheral inflammation. Mol. Pain 1:25. doi: 10.1186/1744-806 9-1-25

Chen, L., Yang, G., and Grosser, T. (2013). Prostanoids and inflammatory pain. Prostaglandins Other Lipid Mediat. 10, 58-66. doi: 10.1016/j.prostaglandins. 2012.08.006

Corrêa, C. R., Kyle, D. J., Chakraverty, S., and Calixto, J. B. (1996). Antinociceptive profile of the pseudopeptide B2 bradykinin receptor antagonist NPC 18688 in mice. Br. J. Pharmacol. 117, 552-558. doi: 10.1111/j.1476-5381.1996.tb15226.x

Díaz-González, F., and Sánchez-Madrid, F. (2015). NSAIDs: learning new tricks from old drugs. Eur. J. Immunol. 45, 679-686. doi: 10.1002/eji.201445222

Dougherty, P. M., Palecek, J., Paleckova, V., Sorkin, L. S., and Willis, W. D. (1992). The role of NMDA and non-NMDA excitatory amino acid receptors in the excitation of primate spinothalamic tract neurons by mechanical, chemical, thermal, and electrical stimuli. J. Neurosci. 12, 3025-3041. doi: 10. 1523/JNEUROSCI.12-08-03025.1992 
Dougherty, P. M., and Willis, W. D. (1992). Enhanced responses of spinothalamic tract neurons to excitatory amino acids accompany capsaicin-induced sensitization in the monkey. J. Neurosci. 12, 883-894. doi: 10.1523/JNEUROSCI.12-03-00883.1992

Dubuisson, D., and Dennis, S. G. (1977). The formalin test: a quantitative study of the analgesic effects of morphine, meperidine, and brain stem stimulation in rats and cats. Pain 4, 161-174. doi: 10.1016/0304-3959(77)90130-0

Dwivedi, A. K., Gurjar, V., Kumar, S., and Singh, N. (2015). Molecular basis for nonspecificity of nonsteroidal anti-inflammatory drugs (NSAIDs). Drug Discov. Today 20, 863-873. doi: 10.1016/j.drudis.2015.03.004

Eddy, N. B., and Leimbach, D. (1953). Synthetic analgesics. II. Dithienylbutenyland dithienylbutylamines. J. Pharmacol. Exp. Ther. 107, 385-393.

Espinosa-Sanchez, J. M., and Lopez-Escamez, J. A. (2015). New insights into pathophysiology of vestibular migraine. Front. Neurol. 6:12. doi: 10.3389/fneur. 2015.00012

Ferencik, M., Novak, M., Rovensky, J., and Rybar, I. (2001). Alzheimer's disease, inflammation and non-steroidal anti-inflammatory drugs. Bratisl. Lek. Listy $102,123-132$.

Gargallo, C. J., and Lanas, A. (2013). Is NSAIDs-related gastrointestinal damage preventable? J. Dig. Dis. 14, 55-61. doi: 10.1111/1751-2980.12019

Gong, J., Lai, Y., Li, X., Wang, M., Leitz, J., Hu, Y., et al. (2016). C-terminal domain of mammalian complexin-1 localizes to highly curved membranes. Proc. Natl. Acad. Sci. U.S.A. 113, E7590-E7599. doi: 10.1073/pnas.1609917113

Gong, K. R., Cao, F. L., He, Y., Gao, C. Y., Wang, D. D., Li, H., et al. (2010). Enhanced excitatory and reduced inhibitory synaptic transmission contribute to persistent pain-induced neuronal hyper-responsiveness in anterior cingulate cortex. Neuroscience 171, 1314-1325. doi: 10.1016/j.neuroscience.2010.10.028

Iwata, R., Kitagawa, K., Zhang, N. Y., Wu, B., and Inagaki, C. (2004). Non-steroidal anti-inflammatory drugs protect amyloid beta protein-induced increase in the intracellular $\mathrm{Cl}$ - concentration in cultured rat hippocampal neurons. Neurosci. Lett. 367, 156-159. doi: 10.1016/j.neulet.2004.05.103

Ji, R. R., Gereau, R. W. IV, Malcangio, M., and Strichartz, G. R. (2009). MAP kinase and pain. Brain Res. Rev. 60, 135-148. doi: 10.1016/j.brainresrev.2008.12.011

Jiangsu New Medical College (1977). Zhong Yao Da Ci Dian. Shanghai: Shanghai Scientific and Technical Publishers.

Klasser, G. D., and Epstein, J. (2005). Nonsteroidal anti-inflammatory drugs: confusion, controversy and dental implications. J. Can. Dent. Assoc. 71, 575580. doi:

Koga, K., Matsuzaki, Y., Honda, K., Eto, F., Furukawa, T., Migita, K., et al. (2017). Activations of muscarinic M1 receptors in the anterior cingulate cortex contribute to the antinociceptive effect via GABAergic transmission. Mol. Pain 13:1744806917692330. doi: 10.1177/1744806917692330

Laedermann, C. J., Cachemaille, M., Kirschmann, G., Pertin, M., Gosselin, R. D., Chang, I., et al. (2013). Dysregulation of voltage-gated sodium channels by ubiquitin ligase NEDD4-2 in neuropathic pain. J. Clin. Invest. 123, 3002-3013. doi: 10.1172/JCI68996

Liu, S. H., Chuang, W. C., Lam, W., Jiang, Z., and Cheng, Y. C. (2015). Safety surveillance of traditional Chinese medicine: current and future. Drug Saf. 38, 117-128. doi: 10.1007/s40264-014-0250-z

Marchand, F., Perretti, M., and McMahon, S. B. (2005). Role of the immune system in chronic pain. Nat. Rev. Neurosci. 6, 521-532. doi: 10.1038/ nrn 1700

Mickle, A. D., Shepherd, A. J., and Mohapatra, D. P. (2015). Sensory TRP channels: the key transducers of nociception and pain. Prog. Mol. Biol. Transl. Sci. 131, 73-118. doi: 10.1016/bs.pmbts.2015.01.002

Moore, R. A., Derry, S., Simon, L. S., and Emery, P. (2014). Nonsteroidal antiinflammatory drugs, gastroprotection, and benefit-risk. Pain Pract. 14, 378-395. doi: 10.1111/papr.12100

Peng, X. L., Gao, X. L., Chen, J., Huang, X., and Chen, H. S. (2003). Effects of intravenous injections paederiae and stauntonia on spontaneous pain, hyperalgesia and inflammation induced by cutaneous chemical tissue injury in the rat. Sheng Li Xue Bao 55, 516-524.

Ren, K., Hylden, J. L., Williams, G. M., Ruda, M. A., and Dubner, R. (1992). The effects of a non-competitive NMDA receptor antagonist, MK801 , on behavioral hyperalgesia and dorsal horn neuronal activity in rats with unilateral inflammation. Pain 50, 331-344. doi: 10.1016/0304-3959(92) 90039-E
Rosenmund, C., and Stevens, C. F. (1996). Definition of the readily releasable pool of vesicles at hippocampal synapses. Neuron 16, 1197-1207. doi: 10.1016/ S0896-6273(00)80146-4

Schaible, H. G., Ebersberger, A., and Von Banchet, G. S. (2002). Mechanisms of pain in arthritis. Ann. N. Y. Acad. Sci. 966, 343-354. doi: 10.1111/j.1749-6632. 2002.tb04234.x

Schaible, H. G., Grubb, B. D., Neugebauer, V., and Oppmann, M. (1991). The Effects of NMDA antagonists on neuronal activity in cat spinal cord evoked by acute inflammation in the knee joint. Eur. J. Neurosci. 3, 981-991. doi: 10.1111/j.1460-9568.1991.tb00034.x

Simon, L. S. (2013). Nonsteroidal anti-inflammatory drugs and their risk: a story still in development. Arthritis Res. Ther. 15(Suppl. 3):S1. doi: 10.1186/ar4173

Spindola, H. M., Servat, L., Denny, C., Rodrigues, R. A., Eberlin, M. N., Cabral, E., et al. (2010). Antinociceptive effect of geranylgeraniol and 6alpha, 7beta-dihydroxyvouacapan-17beta-oate methyl ester isolated from Pterodon pubescens Benth. BMC Pharmacol. 10:1. doi: 10.1186/1471-2210-10-1

Talbot, J. D., Marrett, S., Evans, A. C., Meyer, E., Bushnell, M. C., and Duncan, G. H. (1991). Multiple representations of pain in human cerebral cortex. Science 251, 1355-1358. doi: 10.1126/science.2003220

Tian, J., Tian, Z., Qin, S. L., Zhao, P. Y., Jiang, X., and Tian, Z. (2017). Anxiolyticlike effects of $\alpha$-asarone in a mouse model of chronic pain. Metab. Brain Dis. 32, 2119-2129. doi: 10.1007/s11011-017-0108-z

Wang, C., Liu, C., Wan, H., Wang, D., Sun, D., Xu, T., et al. (2015). Wu-tou decoction inhibits chronic inflammatory pain in mice: participation of TRPV1 and TRPA1 ion channels. Biomed. Res. Int. 2015:328707. doi: 10.1155/2015/ 328707

Xiong, W., Ping, X., Ripsch, M. S., Chavez, G. S. C., Hannon, H. E., Jiang, K., et al. (2017). Enhancing excitatory activity of somatosensory cortex alleviates neuropathic pain through regulating homeostatic plasticity. Sci. Rep. 7:12743. doi: 10.1038/s41598-017-12972-6

Xu, J., Wang, S., Feng, T. H., Chen, Y., and Yang, G. Z. (2018). Hypoglycemic and hypolipidemic effects of total saponins from Stauntonia chinensis in diabetic db/db mice. J. Cell. Mol. Med. doi: 10.1111/jcmm.13876 [Epub ahead of print].

Xu, Q., Wang, Y., Guo, S., Wang, Y., and Yang, L. (2014). Anti-inflammatory and analgesic activity of aqueous extract of Flos populi. J. Ethnopharmacol. 152, 540-545. doi: 10.1016/j.jep.2014.01.037

Xue, C. C., Zhang, A. L., Greenwood, K. M., Lin, V., and Story, D. F. (2010). Traditional chinese medicine: an update on clinical evidence. J. Altern. Complement Med. 16, 301-312. doi: 10.1089/acm.2009.0293

Ye, W. B., Zhang, H. Q., and Jin, R. H. (2003). The effect of Stauntoniae saponinon axon membrane and myelin in sheath of the rat saphenous nerve. Chinese J. Neuroanat. 19, 311-316.

Ying, C., Ning, W., Ying, L., Hao, G., Hua-Jin, D., Rui-Bin, S., et al. (2014). Anti-nociceptive and anti-inflammatory activities of the extracts of Stauntonia chinensis. Pak. J. Pharm. Sci. 27, 1317-1325.

Yue, J., Wang, X. S., Guo, Y. Y., Zheng, K. Y., Liu, H. Y., Hu, L. N., et al. (2017). Anxiolytic effect of CPEB1 knockdown on the amygdala of a mouse model of inflammatory pain. Brain Res. Bull. 137, 156-165. doi: 10.1016/j.brainresbull. 2017.12.002

Zhang, Y., Wang, C., Wang, L., Parks, G. S., Zhang, X., Guo, Z., et al. (2014). A novel analgesic isolated from a traditional Chinese medicine. Curr. Biol. 24, 117-123. doi: 10.1016/j.cub.2013.11.039

Zhou, L. N., and Ye, W. B. (2011). Neuroprotective and growth promoting effects of injection stauntoniae and extracts on mice spinal neuron. J. Shanghai Normal University 40, 540-545.

Conflict of Interest Statement: The authors declare that the research was conducted in the absence of any commercial or financial relationships that could be construed as a potential conflict of interest.

Copyright (C) 2018 Chen, Rong, Liu, Cheng, Liu, Li, Yu, Yang and Yang. This is an open-access article distributed under the terms of the Creative Commons Attribution License (CC BY). The use, distribution or reproduction in other forums is permitted, provided the original author(s) and the copyright owner(s) are credited and that the original publication in this journal is cited, in accordance with accepted academic practice. No use, distribution or reproduction is permitted which does not comply with these terms. 